\title{
Y-1 papers, white paper, Chinese mortality, BC ingredient disclosure, SRNT, PANNA, foundation watch, plus youth shoplifting
}

Web Watch follows issues relevant to tobacco control on the world wide web. The emphasis is on new sites or new features appearing on the web including relevant URLs and short descriptions of the material. A web site is available featuring the URL links referenced in this column as well as those referenced in past columns; the URL for that site is: <http://www. gate.net/ jcannon/webwatch/>.

The Y-1 papers

$<$ http://www.gate.net/ jcannon/y-1/>

The Autumn 1998 issue of Tobacco Control (1998;7:315-9) featured Todd Lewan's Associated Press investigative report entitled, "Dark secrets of tobacco company exposed". A website has been produced that is organised around this article, plus several other documents that provide additional background on the production of the high-nicotine tobacco plant code-named "Y-1" by Brown \& Williamson.
Of particular interest are three sets of minutes of a secret meeting of BAT's Tobacco Strategy Review Team. Along with an accompanying memo, these documents may prove useful in the US Justice Department's criminal investigation of Brown \& Williamson.

Graphics provided by the Associated Press include a Y-1 timeline, a pictorial of the human body showing how smoking harms it, and a global distribution map showing where Y-1 was grown, tested, and used throughout the world (figure 1).

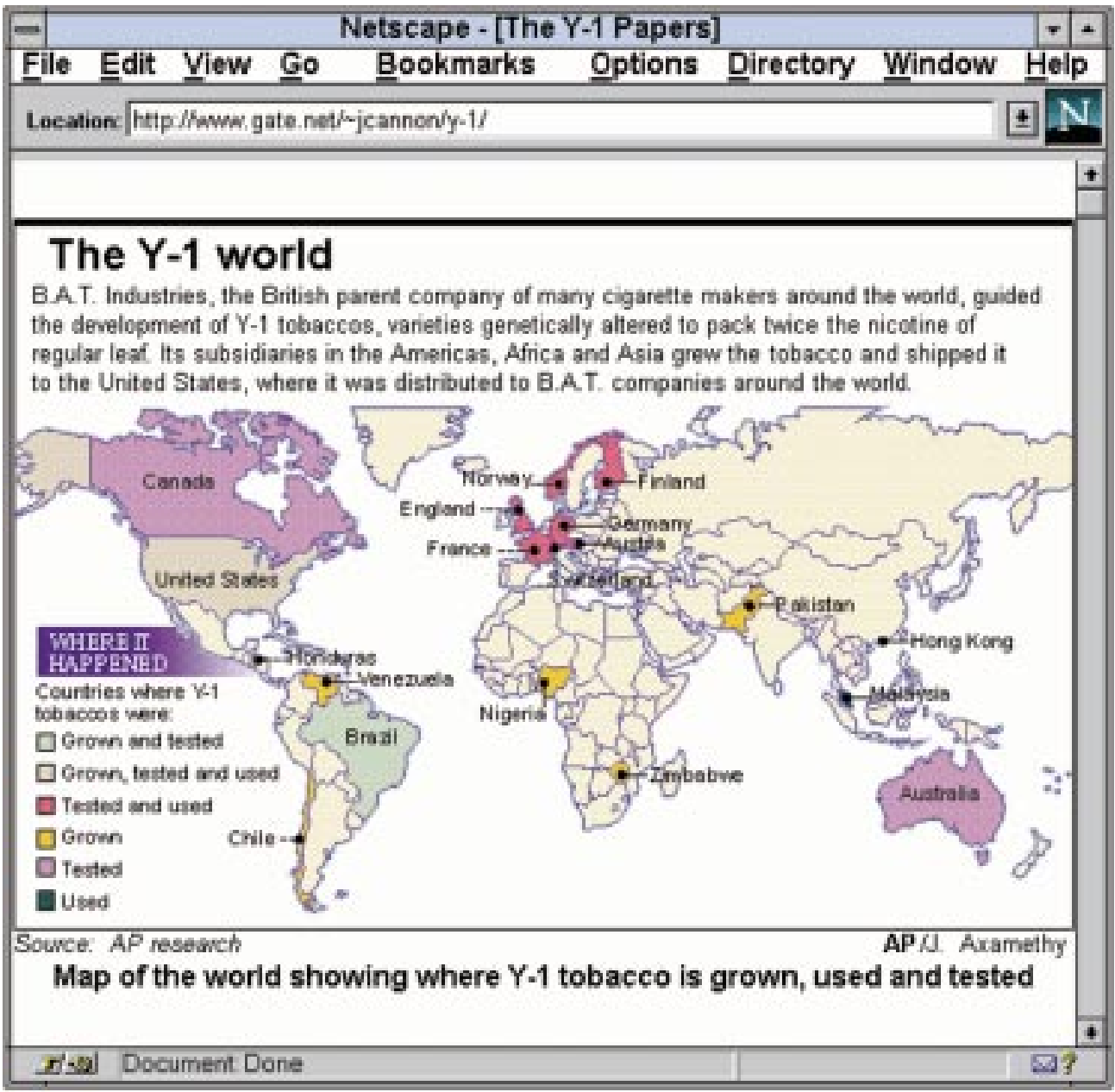

Web Watch is prepared by fack Cannon. Send correspondence to him by email:

(jcannon@gate.net). 
"Smoking Kills"-white paper

$<h t t p: / / w w w . d o h . g o v . u k / s m o k e . h t m>$

Smoking is the United Kingdom's single greatest cause of preventable illness and early death. No surprise here.

With more than 120000 people in the United Kingdom dying each year from smoking, plus annual costs of up to $£ 1.7$ billion, this white paper details a strategy that commits $£ 100$ million to a concerted effort of prevention, cessation, and help for those most affected by nicotine addiction.

Presented to Parliament by the Secretary of State for Health and the Secretaries of State for Scotland, Wales, and Northern Ireland, objectives include: a publicity campaign to shift attitudes and change behaviour; measures to reduce the amount of smoking in public places; a new code of practice to protect people from exposure to secondhand smoke at their place of work; and implementation of Directive 98/43/EC within the UK by 30 July 2006 .

The British Broadcasting Company (BBC) has solicited comments on the white paper. The questions proposed by the BBC are: Is the government's white paper half-hearted because it omits to ban smoking in the workplace or in public places? Is the "nanny state" acceptable if it means saving lives?

An exhaustive list of the responses has been compiled and is available at:

<http://news.bbc.co.uk/hilenglish/question_timel your_comments/newsid_232000/232705.stm>

Emerging tobacco hazards in China

<http://www.ctsu.ox.ac.uk/tobacco/>

With smoking-related mortality rates surpassing those of the United States, China has the unfortunate distinction of hosting more such deaths than any other country. Tobacco claims 2000 Chinese citizens every day and that figure is expected to rise to 8000 by the year 2050 . This equates to approximately 3 million a year or a third of its men if current smoking patterns persist.

Such conclusions are the result of research by the Chinese Academies of Preventive Medicine and Medical Sciences in collaboration with Oxford University (United Kingdom) and Cornell University (Ithaca, New York, United States). These findings are all the more startling given the fact that smoking rates among young Chinese women have undergone a dramatic yet inexplicable decrease since 1950. "Chinese adults severely underestimate smoking risks", according to Oxford professor Richard Peto, and "two-thirds believe smoking does little or no harm".

Two studies were conducted, published by the British Medical fournal (1998;317:141122). The objective was to assess the hazards at an early phase of the growing epidemic of deaths from tobacco in China and to monitor the future growth of the epidemic.

In the "retrospective proportional mortality study of one million deaths", the families of one million deceased individuals were interviewed to find out whether the deceased had smoked. It compared the smoking behaviour of 700000 adults who had died of cancer, respiratory, or vascular causes with those of a "reference group" of 0.2 million adults who had died of other causes.

<http://www.bmj.com/cgi/content/full/317/7170/ 1411>

In the article on "early mortality results from a prospective study" (BMF 1998;317:1423-4), the investigators interviewed, examined, and carried out medical tests on 225000 men aged 40 and older. Mortality and causes of death have been monitored by annual visits. This prospective study will continue for decades, tracing the growth of the epidemic.

<http://www.bmj.com/cgi/content/full/317/7170/ 1423>

The Nuffield Department of Clinical Medicine at Oxford University has provided the above link to each of the studies plus a link to an editorial in the $B M \mathcal{F}(1998 ; 317: 1499-$ 1400), "Counting the dead in Chinameasuring tobacco's impact in the developing world".

$<h t t p: / / w w w . b m j . c o m / c g i / c o n t e n t / f u l l / 317 / 7170 /$

1399>

\section{Ingredient disclosure from British \\ Columbia \\ $<$ <ttp://www.cctc.ca/bcreports/> (English) \\ $<$ http://www.cctc.ca/rapportscb/> (French)}

On 31 July 1998, the government of British Columbia (BC), operating under authority of "The Tobacco Testing and Disclosure Regulation", required tobacco companies to reveal the additives and ingredients in each brand of cigarettes sold in BC.

Additionally the 11 brands that make up half of the cigarettes sold in the province must provide a detailed chemical analysis of the smoke from each brand. Manufacturers must test both sidestream and mainstream smoke from their cigarettes for 44 specific substances. Vent blocking and increased puffing are hallmarks of the improved testing procedures, developed in part by Neil Collishaw and Murray Kaiserman.

Contrary to the belief that many smokers have that "light" cigarettes are less hazardous than regular cigarettes, BC's new smoking tests have shown how wrong this belief can be. These test results show that light cigarettes are likely to deliver as many (or more) poisons and toxins to smokers as do regular cigarettes.

The complete report for each brand is provided, as is a comparison of the levels of each chemical.

Of significant interest is a compilation of key quotes from the United States Department of Health and Human Services, the US Environmental Protection Agency, and Health Canada about the chemicals tested.

\section{Society for Research on Nicotine and \\ Tobacco \\ $<h t t p: / / w w w . s r n t . o r g />$}

The mission of the Society for Research on Nicotine and Tobacco (SRNT) (figure 2) is to 


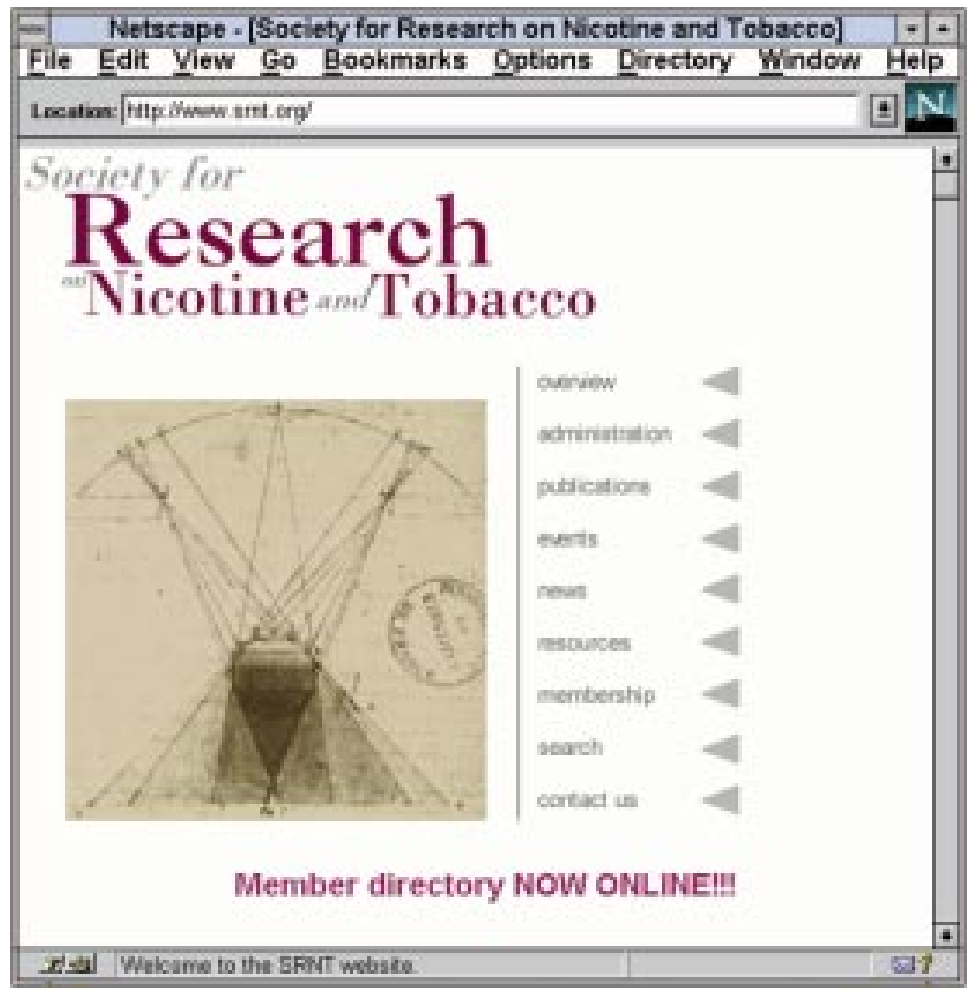

Figure 2 The website for the Society for Research on Nicotine and Tobacco.

stimulate the generation of new knowledge concerning nicotine in all its manifestationsfrom molecular to societal. Its goals are:

- To sponsor scientific meetings and publications fostering the exchange of information on the biological, behavioural, social, and economic effects of nicotine; these activities shall include basic research and research on mechanisms of action and the use of nicotine as a probe for studying nervous systems function as well as applied research on the behavioural and pharmacological aspects of tobacco use, nicotine dependence, the therapeutic uses of nicotine, and related areas.

- To encourage scientific research on public health efforts for the prevention and treatment of cigarette and tobacco use.

- To provide the means by which various legislative, governmental, regulatory, and other public agencies and the ethical drug industry can obtain expert advice and consultation on critical issues concerning tobacco use, nicotine dependence, and the therapeutic uses of nicotine.

A particularly useful resource on the SRNT website is its library of newsletters, which includes a search engine. Meeting notices and a message board are also included.

Dr Jack Henningfield, an associate editor of Tobacco Control, currently serves as president of SRNT.

Pesticide Action Network North America $<$ http://www.igc.org/panna/pubs/tobacco/ contents.html>

Pesticide Action Network North America (PANNA) has campaigned to replace pesticides with ecologically sound alternatives since 1982. The strategy is to link more than 130 affiliated health, consumer, labour, environmental, progressive agriculture, and public interest groups in Canada, Mexico, and the United States with more than 400 partners worldwide to promote healthier, more effective pest management through education, media, demonstrations of alternatives, and international advocacy campaigns.

The medical and scientific evidence of tobacco's cancer-causing effects are widely known. However, less publicised are the thousands of additives and pesticide residues found in cigarettes that are potentially damaging to smokers' health. Furthermore, smoking tobacco not only directly impacts the lives of smokers, but exacts a deep toll on the lives of tobacco farmers and their families and the environment. As tobacco companies move into developing countries to take advantage of cheap labour and land, they bring with them a range of health, environmental, and social problems.

One reason for the low price of imported tobacco is that much of the direct and indirect production costs are quietly absorbed by farmers, their families, and the environment in southern countries where tobacco is grown. A general lack of environmental, pesticide, and labour regulations makes developing countries fertile ground for expansion of the tobacco industry.

To ensure an endless supply of inexpensive cigarettes and cigars and high profits for tobacco companies, millions of pounds of toxic chemicals are being used on millions of acres of land around the world-land that in most cases could be used to grow food. Viewed in a global context, tobacco not only endangers the lives of smokers, it threatens the health and well being of millions of tobacco farmers and workers in countries around the world.

\section{Capital Research Center Foundation Watch}

<http://www.capitalresearch.org/fw/fw-0898. html> Established in 1984 to study non-profit organisations, the Capital Research Center focuses on American traditions of charity, philanthropy, and volunteerism. It specializes in analysing and reporting on organisations with tax-exempt, tax-deductible dollars that mix advocacy and direct action to promote the public interest.

Capital Research claims to provide the tools to understand where philanthropic contributions are spent, and how effectively they are used. Their perspective on the institutions and personalities shaping public opinion and affecting public policy is an integral segment of their endeavours.

One product of the centre sure to be of interest to tobacco control is their analysis of the organisations that supported the 20 June 1997 "settlement agreement" between the tobacco industry and the state attorneys general who sued the industry. That analysis is available at the above URL. 
Their conclusion: although the failure of the 20 June settlement "reduces the chances of another large bill passing Congress anytime soon, comprehensive anti-tobacco legislation will be back because the anti-tobacco lobbies are just beginning." They "almost held their own against the immensely wealthy and politically savvy tobacco industry. If and when they return to Capitol Hill, it will be with a vengeance."

\section{ALAC shoplifting project}

$<$ <ttp://www.smokescreen.org/alac/>

From the American Lung Association of Colorado (ALAC), Anne Landman and April Vawter have produced this site, detailing the subversive actions of the tobacco industry in creating environments necessary to entice children to shoplift cigarettes.

"Big Tobacco's seldom told plan for our children" provides outstanding examples of specific tactics to make it very easy for children to obtain cigarettes that they would otherwise be unable to purchase legally.

An analysis of Safeway, Rite Aid, and K-Mart stores plus several convenience stores in Colorado and Georgia shows single-pack displays near bulk candy displays, stuffed animals, and doorways. Direct viewing by clerks is usually obscured by other store displays.

"Placement" fees paid by the tobacco industry more than compensate for the stolen product. In fact, retailers reveal that these "placement" fees can easily net them an additional US $\$ 10000$ per year for each store.

One cooperative retailer moved their tobacco out of view. The cigarettes were moved to the overhead bin while cartons and spit tobacco were moved under and behind the counter. Sales did not drop at all while losses went from 300 packs a month to four.

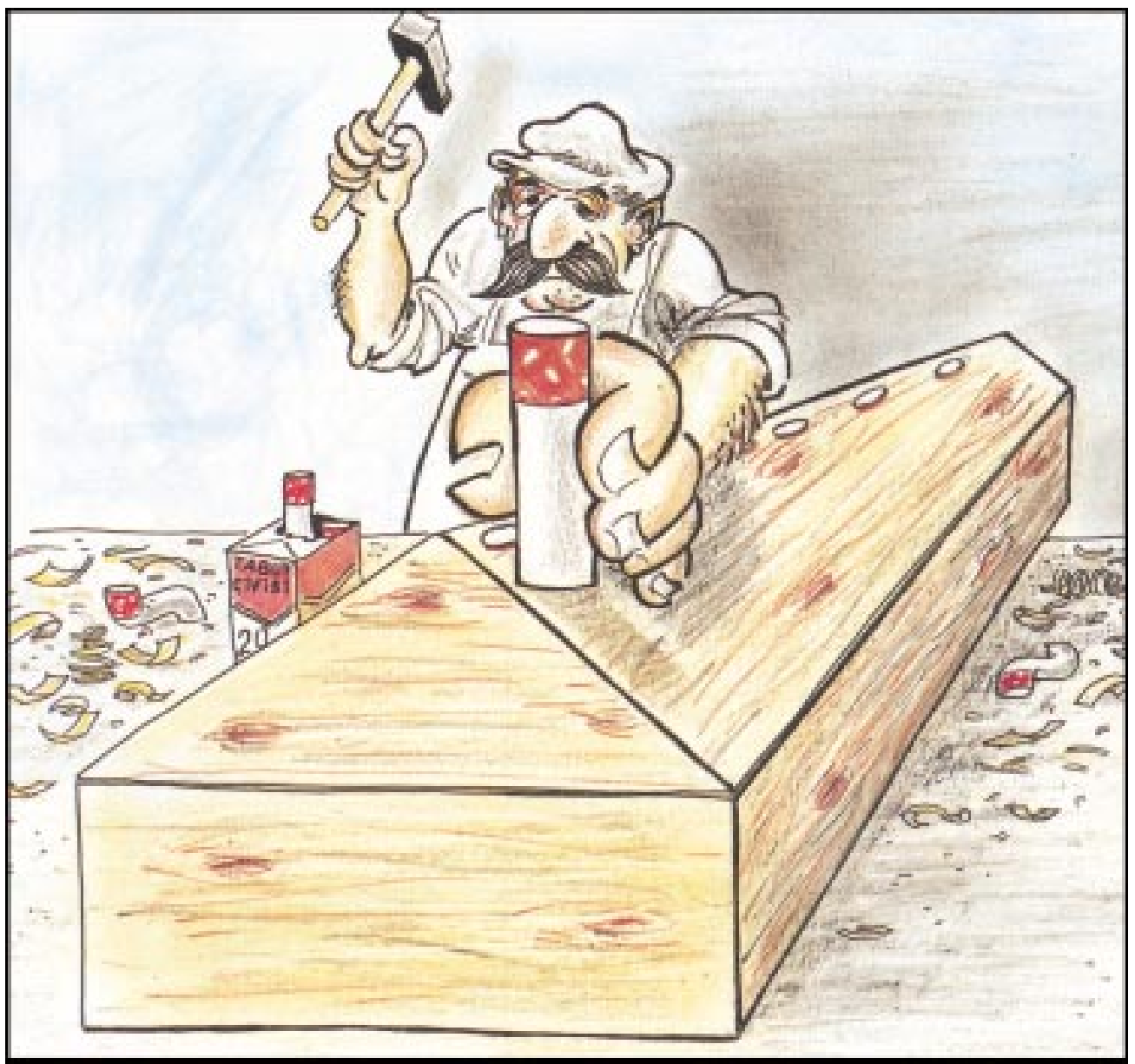

By Uĝur Pamuk (Turkey). 